\title{
Evaluation of intra-ring wood density profiles using NIRS: comparison with the $\mathrm{X}$-ray method
}

\author{
Ricardo Baettig $^{1}$ (I) $\cdot$ Jorge Cornejo $^{2} \cdot$ Jorge Guajardo $^{1}$
}

Received: 24 February 2016 / Accepted: 22 November 2016 / Published online: 15 February 2017

(C) INRA and Springer-Verlag France 2017

\begin{abstract}
- Key message Pith-to-bark wood density profiling is interesting in forestry science. By comparing it with the X-ray method, this study proved that a fiber optic NIR spectrometer with a high-precision displacement system could accurately measure intra-ring wood density with a spatial resolution of $0.5 \mathrm{~mm}$.

- Context Most near-infrared spectroscopy (NIRS) studies for wood density determination use samples that have been pulverized beforehand. Attenuation of ionizing radiation is still the standard method to determine wood density with high spatial resolution. However, there is evidence that NIRS could be an accurate and affordable method for determining intraring density in solid wood strips.

- Aims In this study, we research whether the results published for intra-ring density predictions in wood can be improved when calibrated with X-ray microdensitometry.
\end{abstract}

Handling Editor: Jean-Michel Leban

Contribution of the co-authors Ricardo Baettig: design of the experiment; write the manuscript; supervise the data analysis.

Jorge Cornejo: write the manuscript.

Jorge Guajardo: execute the measurements, run the statistical procedures.

Ricardo Baettig

rbaettig@utalca.cl

Jorge Cornejo

jocornejo@utalca.cl

Jorge Guajardo

jorguajardo@utalca.cl

1 Facultad de Ciencias Forestales, Poplar Technol Ctr, Univ Talca, POB 747, Talca, Chile

2 Inst Nat Resources Chem, Univ Talca, POB 747, Talca, Chile
- Methods The measurements were made using a fiber optic probe with a separation between measurement points of $0.508 \mathrm{~mm}$ in a range between 1200 and $2200 \mathrm{~nm}$. A total of 4520 density points were used to create partial least squares regression (PLSR). X-ray densitometry data were used as reference values. Twenty PLSR calibrations were randomly executed on 31 samples collected from 28 Pinus radiata D. Don trees.

- Results Upon selecting 20 latent variables, the $R^{2}$ value was 0.873 for the training group and 0.895 for the validation group, while RMSEP values are $43.1 \times 10^{-3}$ and $47.1 \times 10^{-3} \mathrm{~g} \mathrm{~cm}^{-3}$ for the training and validation groups, respectively. The range error ratio (RER) was 13.7.

- Conclusion The RER was high and almost in the range suggested for quantification purposes. Results are superior to wood density studies in the literature which do not employ spatial resolution and to those found in studies using hyperspectral imaging.

Keywords Wood rings $\cdot \mathrm{X}$-ray densitometry $\cdot$ Partial least squares regression $\cdot$ Diffuse reflectance spectroscopy

\section{Introduction}

Near-infrared spectroscopy (NIRS) is an effective method for predicting many properties of wood such as density, not only in the laboratory but also in the field ( $\mathrm{Li}$ et al. 2012). Multivariate statistical methods such as principal component analysis (PCA), principal component regression (PCR), and partial least squares regression (PLSR) are generally used to obtain prediction models (Tsuchikawa 2007). Neural networks are used to a lesser extent to obtain these models ( $\mathrm{Li}$ et al. 2012). The NIR/PLSR combination is the most widely used to estimate wood density quickly, simply, and at low 
cost. To improve the prediction models, diverse data processing techniques are used, including derivatives, multiplicative scatter correction (MSC), and standard normal variate (SNV). The most common quality criteria for measuring prediction models are high coefficients of determination $\left(R^{2}\right)$ and minimum values of root-mean-square error of prediction (RMSEP) in a validation group consisting of an independent sample group.

Most of the time, diffuse reflectance spectra are recorded in samples that have been pulverized beforehand; few wood density studies have been conducted at high spatial resolution or at the intra-ring level (microdensity). In density estimations of pulverized samples or wood chips, coefficients of determination of 0.80 have been achieved in the validation group for Eucalyptus globulus Labill (Schimleck et al. 1999), 0.91 for Eucalyptus delegatensis R.T. Baker (Schimleck et al. 2001), 0.84 for Pinus taeda L. (Mora et al. 2008), 0.85 for Pseudotsuga menziesii (Mirb.) Franco (Acuna and Murphy 2007), and 0.84 for Eucalyptus spp. (Downes et al. (2011). In non-pulverized samples of Eucalyptus grandis W. Hill ex Maiden, Rosso et al. (2013) obtained a coefficient of determination of 0.74 with radial scanning of samples. Haddadi et al. (2015) scanned a total of 107 cubic samples of $4 \mathrm{~cm}$ size in Abies lasiocarpa Hook in a spectral range from 947 to $1637 \mathrm{~nm}$ (spectral resolution of $3.3 \mathrm{~nm}$ ). The relationship with gravimetric density showed a $R^{2}$ and RMSEP of 0.81 and $39.5 \times 10^{-3} \mathrm{~g} \mathrm{~cm}^{-3}$, respectively. Calibration of NIR to build microdensity profiles was first carried out by Schimleck and Evans (2003), who studied two increment cores to calibrate an NIR/PLS model with a spatial resolution of $10 \mathrm{~mm}$, using as reference data those provided by the SilviScan-2. The NIR range used was between 1100 and $2500 \mathrm{~nm}$ and they recorded the diffuse reflectance spectra with a separation of $2 \mathrm{~mm}$ between consecutive points, in a moving window of $5 \times 10 \mathrm{~mm}$. The authors obtained $R^{2}$ values of 0.95 and 0.92 and RMSEP values of $34.8 \times 10^{-3}$ and $62.3 \times 10^{-3} \mathrm{~g} \mathrm{~cm}^{-3}$ for each increment core. Jones et al. (2007) studied 15 radial wooden strips cut from increment cores with five NIR devices from different manufacturers. The spectral range varied from 350 to $2500 \mathrm{~nm}$, depending on the equipment model. They studied two different spatial resolutions: 2 and $5 \mathrm{~mm}$. The best results were obtained for a spatial resolution of $5 \mathrm{~mm}$ with $R^{2}$ values from 0.76 to 0.53 and RMSEP values from $61.5 \times 10^{-3}$ to $97.1 \times 10^{-3} \mathrm{~g} \mathrm{~cm}^{-3}$. In E. globulus, Wentzel-Vietheer et al. (2013) studied 175 pit-to-bark cores at $1 \mathrm{~mm}$ interval in a wave number range from $10,000 \mathrm{~cm}^{-1}(1000 \mathrm{~nm})$ to $4000 \mathrm{~cm}^{-1}(2500 \mathrm{~nm})$. Using data from the SilviScan-3 as reference, the $R^{2}$ and RMSECV obtained were 0.64 and $96.3 \times 10^{-3} \mathrm{~g} \mathrm{~cm}^{-3}$, respectively. Downes et al. (2014) remade the previous study using 266 pith-to-bark radial strips at $1 \mathrm{~mm}$ interval and averaged at $5 \mathrm{~mm}$ in the radial direction. Similarly, and using SilviScan-3 as reference, the $R^{2}$ and RMSEE obtained were 0.78 and $47.6 \times 10^{-3} \mathrm{~g} \mathrm{~cm}^{-3}$, respectively. Likewise, Rodrigues et al. (2013) used an FTNIR analyzer to measure a single pith-to-bark density, in a range between 12,500 and $4000 \mathrm{~cm}^{-1}$ ( 800 to $2500 \mathrm{~nm}$ ), with a spatial resolution close to $1 \mathrm{~mm}$. The authors obtained a coefficient of determination value between the NIR/PLS method and the X-ray method of 0.98 with a root-meansquared error of $22.7 \times 10^{-3} \mathrm{~g} \mathrm{~cm}^{-3}$. However, they had to remove 31 of the 83 points contained in the validation group. On the other hand, detailed measurement of the intra-ring density profile using the NIR/PLS method can be performed with hyper spectral imaging system technology. Fernandes et al. (2013a) used this technology at a spatial resolution of $0.6 \mathrm{~mm}$ in a spectral range from 380 to $1028 \mathrm{~nm}$ and obtained a coefficient of determination value between the NIR/PLS method and the X-ray method of 0.810 (for close to 17,000 points) with an RMSEP value of $65.4 \times 10^{-3} \mathrm{~g} \mathrm{~cm}^{-3}$. Using neural networks, these values improved to 0.821 and $62.5 \times 10^{-3} \mathrm{~g} \mathrm{~cm}^{-3}$ for $R^{2}$ and RMSEP, respectively (Fernandes et al. 2013b). Kitamura and Tsuchikawa (2015) proposed measuring density profiles using attenuation in transmission of an infrared laser at $830 \mathrm{~nm}$, using an avalanche diode as a detector. The best results were achieved with a sample thickness of $0.5 \mathrm{~mm}$ and an RMSEP of $46.0 \times 10^{-3} \mathrm{~g} \mathrm{~cm}^{-3}\left(R^{2}=0.921\right)$ for a validation group composed of 30 measurement points.

The purpose of this study was to investigate whether the results published for NIR/PLS intra-ring density predictions in wood can be improved when calibrated with X-ray microdensitometry. The study considered 31 digital X-ray images with their respective wood samples, which had been in storage for 14 years and were recently scanned using a latest generation fiber optic NIR device.

\section{Material and methods}

\subsection{The experimental setup}

The experimental setup for NIRS was comprised of a nearinfrared spectrometer, a source of light, a bifurcated fiber optic probe, and a Spectralon ${ }^{\circledR}$ reference. The work was performed with 31 tangential/radial samples from pith to cambial zone with a thickness of $2 \mathrm{~mm}$, collected from 28 Pinus radiata D. Don trees. The wood samples were in storage from 2001, when X-ray densitometry was performed, to 2015 when they were measured with NIRS. The wood strips remained stored in a cabinet within airtight plastic bags. The possibility of loss of wood density in these storage conditions can be considered void. The equilibrium moisture content of the wood during NIRS measurement was around $10 \%$. The spectrometer model used was the Ocean Optics NIR Quest with 512 pixels ranging from 900 to $2500 \mathrm{~nm}$ (resolution: $3.18 \mathrm{~nm}$ ). An Instron 3369 mechanical testing machine was used to perform 
the precise linear movements of the wood samples. NIRS measurements were taken every $5.2 \mathrm{~s}$ using a velocity of displacement of $5.862 \mathrm{~mm} \mathrm{~min}^{-1}$, resulting in a distance of $0.508 \mathrm{~mm}$ between points, equivalent to 50 dots per inch (dpi). In a separate experiment, it was estimated that each reading with the fiber optic probe covered a circular area with a spot diameter of approximately $1.4 \mathrm{~mm}$ on the transverse plane (tangential/radial surface) of the wood sample. For typical Chilean P. radiata growth conditions, each tree ring is represented by an average of 14 measurement points, allowing for a detailed analysis within each tree ring. Full spectrum was composed of 346 points, exploiting the range between 1200 and $2200 \mathrm{~nm}$ at a resolution of $3.18 \mathrm{~nm}$. Five scans were collected for a single spectrum with $100 \mathrm{~ms}$ of integration time. The only preprocessing method implemented was $\mathrm{SNV}$, in which the spectrum average is subtracted from each data point and the result is divided by the standard deviation.

\subsection{X-ray densitometry}

The reference values were X-ray images digitized using an Agfa Duos can scanner with 8-bit gray resolution and spatial resolution of $300 \mathrm{dpi}$ equivalent to $0.0847 \mathrm{~mm}$ (Zamudio et al. 2002; Zamudio et al. 2005). Prior to radiation, resins in the wood samples were extracted with alcohol. The density was obtained from the correlation of the gray scale in a polyoxymethylene-copolymer (Kemetal $\left.{ }^{\circledR}\right)$ sample with a known thickness scale to the grayscale in each X-ray image. The predicted mean density for each sample was matched to its density measured using gravimetry, at a moisture content of $10 \%$. To address the different NIR and X-ray resolutions, one of every six pixels in the digital image was used as a reference value, ranging from 300 to $50 \mathrm{dpi}$. The positions for the measurement of NIR spectra and X-ray microdensity were matched as closely as possible. Curvature of the the tree rings in the pathway measured by X-ray and NIR is assumed negligible. A moving average was applied to the $\mathrm{X}$-ray densitometry data with intervals of $1.4 \mathrm{~mm}$. This smoothing could be slightly more intense than the weighting effect produced by the use of a circular fiber optic probe.

\subsection{Partial least squares regression}

A total of 4520 density points from 31 wood samples were used to create partial least squares training and validation groups. The training group was made up of 20 randomly selected samples and the validation contained the remaining 11 samples. Twenty PLSR calibrations were executed randomly with the 31 samples, resulting in 20 samples in the training group and 11 in the validation group. Averaging the results of the 20 calibrations generated a reliable characterization of the quality of the PLSR calibrations (Fernandes et al. 2013a). The data were processed using the PLS package of R (Mevik and Werens 2007). The number of PLSR components was varied from 1 to 20 using the SIMPLS algorithm and leave-one-out (LOO) cross-validation. No outlier detection was used. Method performance was measured using four indicators: the coefficient of determination $\left(R^{2}\right)$, the root-mean-squared error of prediction (RMSEP), the ratio between the RMSEP value of the validation group and the RMSEP value of the training group, and the range error ratio (RER) which is the ratio of the range in validation reference data to the RMSEP. The ratio between the RMSEP obtained from the validation and training groups and the RER calculated from the validation group were used to compare the quality of PLSR results (Alves et al. 2012).
Fig. 1 Mean and standard deviation of RMSEP calculated by 20 PLSR calibrations and as a function of the number of latent variables included

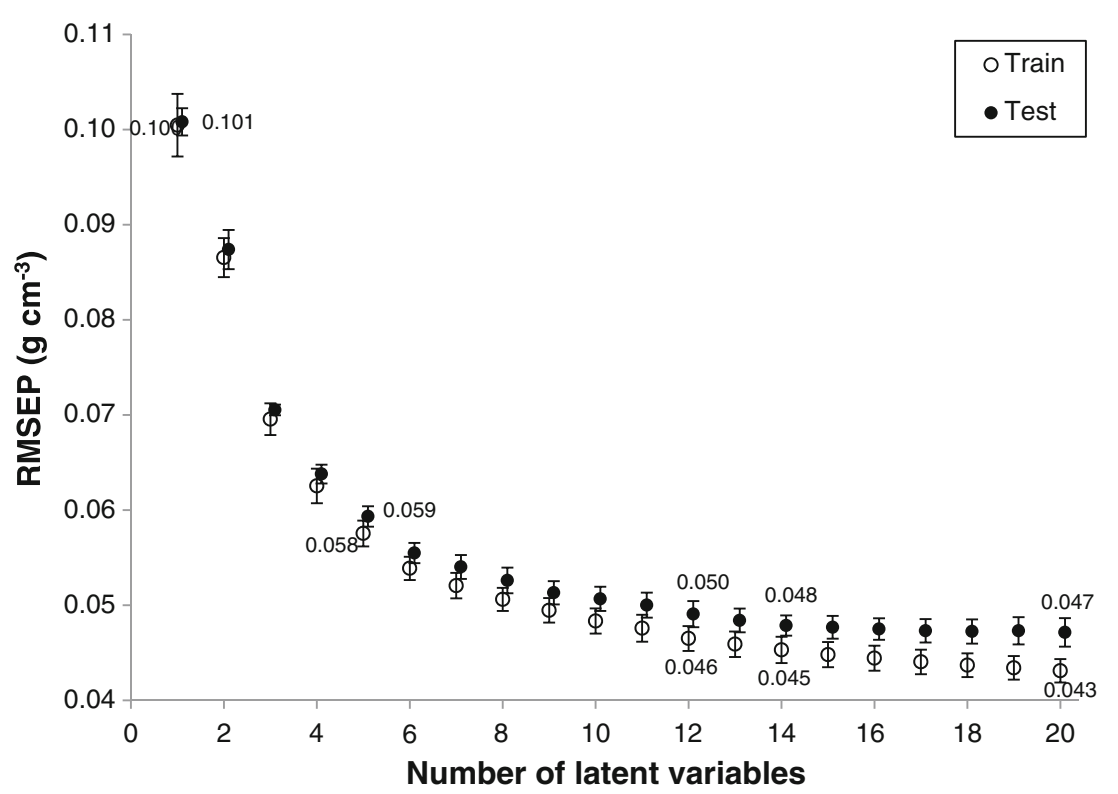


Fig. 2 Mean and standard deviation of $R^{2}$ calculated by 20 PLSR calibrations and as a function of the number of latent variables included

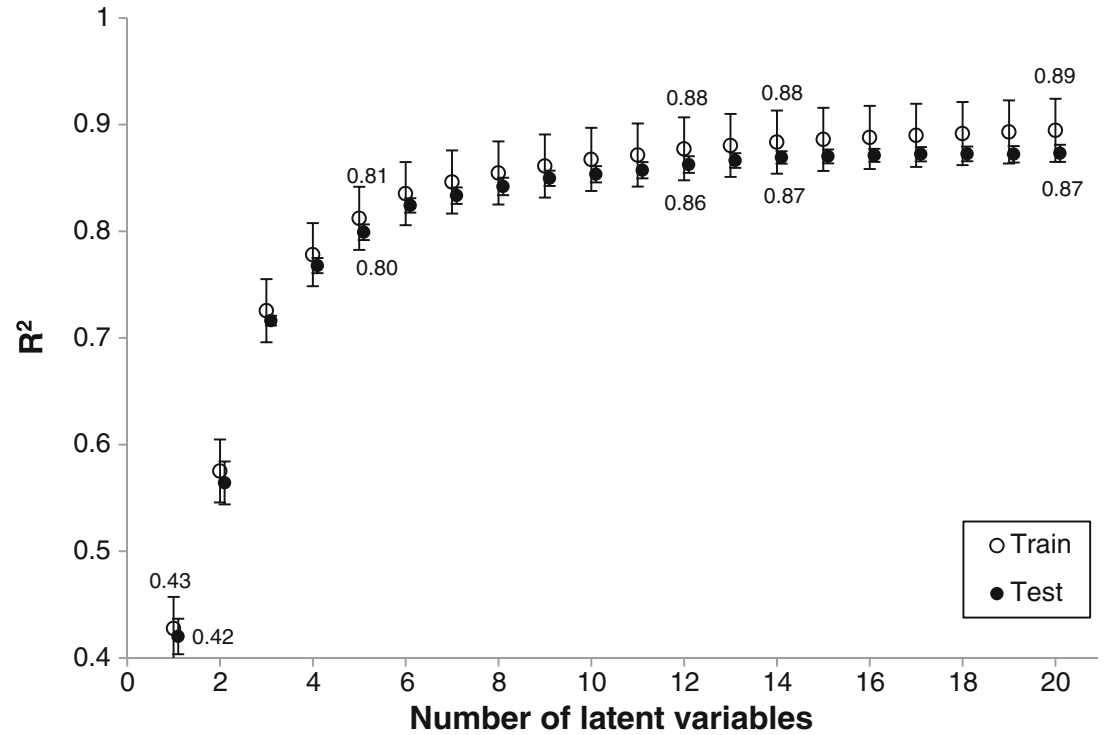

\section{Results}

\subsection{Results varying the number of latent variables}

Figures 1, 2, and 3 plot the mean RMSEP, $R^{2}$, and RER as a function of the number of latent variables. The error bar shows one standard deviation around the mean of the 20 PLSR calibrations generated. This variability around the mean value is limited for the 20 models created. The curves show that using five latent variables produces an RMSEP value below $60 \times 10^{-3} \mathrm{~g} \mathrm{~cm}^{-3}\left(R^{2}>0.8\right)$ while using 12 latent variables produces an RMSEP value under $50 \times 10^{-3} \mathrm{~g} \mathrm{~cm}^{-3}$ $\left(R^{2}>0.86\right)$. Beyond 14 latent variables, the improvement in calibration performance is practically imperceptible; with convergence to an RMSEP value around $42 \times 10^{-3} \mathrm{~g} \mathrm{~cm}^{-3}$ and RER value of approximately 13.7. For 20 latent variables, the
RER mean and standard deviation were $13.7 \pm 0.5$, with raw data ranging from 12.7 to 14.5 .

\subsection{A typical run scatter plots}

Figures 4 and 5 are scatter plots of the reference and predicted values for one "typical run" from 20 PLSR calibrations generated. It should be noted that possible outlier points were not eliminated from any of the 20 PLSR calibrations. These scatter plots indicate that there is systematic underestimation bias of the highest density values (latewood). Figure 6 plots the root-mean-squared error as a percentage (RMSEP\%) for the same data in Figs. 4 and 5. For low-density values (earlywood), the RMSEP\% value is between 20 and $30 \%$, whereas for high-density values (latewood), the RMSEP\% is less than $10 \%$. Although the RMSEP\% is lower in the density
Fig. 3 Mean and standard deviation of RER calculated by 20 PLSR calibrations and as a function of the number of latent variables included

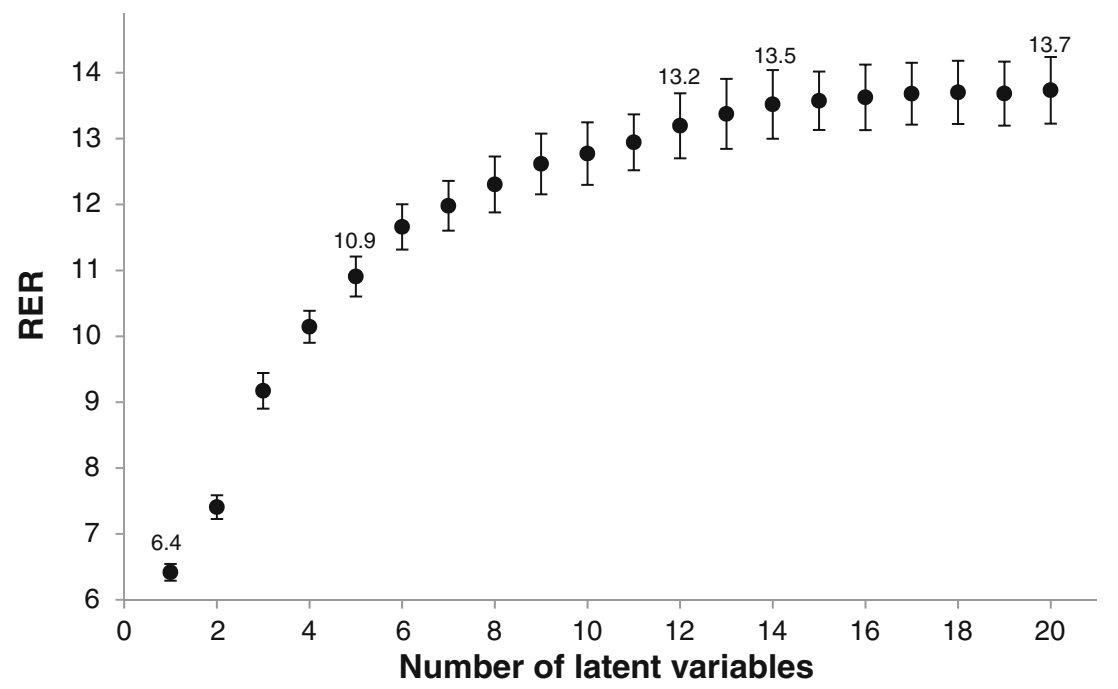


Fig. 4 Scatter plot for the training group for a typical run (20 latent variables included)

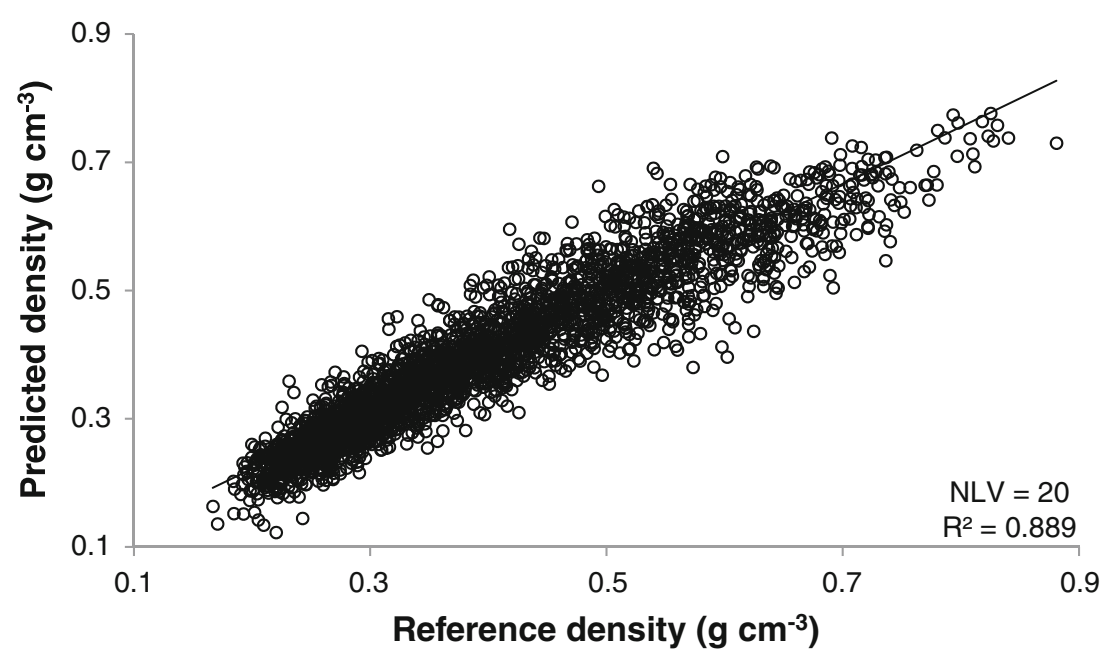

predictions for latewood, it is important to take into account the systematic underestimation bias in these predictions.

\subsection{Intra-ring density profiles}

Figure 7 plots good (a) and poor (b) results for the comparison between X-ray and NIR-predicted microdensity profiles for six wood samples selected from validation groups for two quality extremes of 20 PLSR calibrations. The $R^{2}$ and RMSEP values presented in Fig. 7 are calculated at the individual sample level. Good results are $R^{2}$ values between 0.91 and 0.93 and RMSEP values around $37 \times 10^{-3} \mathrm{~g} \mathrm{~cm}^{-3}$. The worst samples achieve an $R^{2}$ value of 0.797 and an RMSEP value of $62.2 \times 10^{-3} \mathrm{~g} \mathrm{~cm}^{-3}$. Other poor results are $R^{2}$ values between 0.87 and 0.89 and RMSEP values around $45 \times 10^{-3} \mathrm{~g} \mathrm{~cm}^{-3}$. Figure 8 plots the residuals from the predictions for the same six pith-to-bark strips from Fig. 7. The best result was a mean residual value of $-1.8 \times 10^{-3} \mathrm{~g} \mathrm{~cm}^{-3}$ and a mean residual (relative to the reference value) of $-0.5 \%$.
The worst result showed a mean residual value of $-90.1 \times 10^{-3} \mathrm{~g} \mathrm{~cm}^{-3}$ and a mean residual $\%$ of $-22.7 \%$.

\section{Discussion}

For typical Chilean Pinus radiata growth conditions, $0.508 \mathrm{~mm}$ of distance between measurement points mean each tree ring was represented by an average of 14 points, which allows for detailed analysis within each tree ring. The intraring density profiles for Pinus radiata growing in Chile are often very complex due to alterations in the profile shape (false tree rings). The NIR/PLSR method implemented pursues precisely these anomalies in the predicted profiles of tree rings. However, in "poor cases" shown, the high extremes of tree ring density (latewood) are overestimated, while the low extremes (earlywood) may be over- or underestimated.

The mean $R^{2}$ and RMSEP values for NIR/PLSR models relative to $\mathrm{X}$-ray densitometry values are 0.873 and
Fig. 5 Scatter plot for the validation group for a typical run (20 latent variables included)

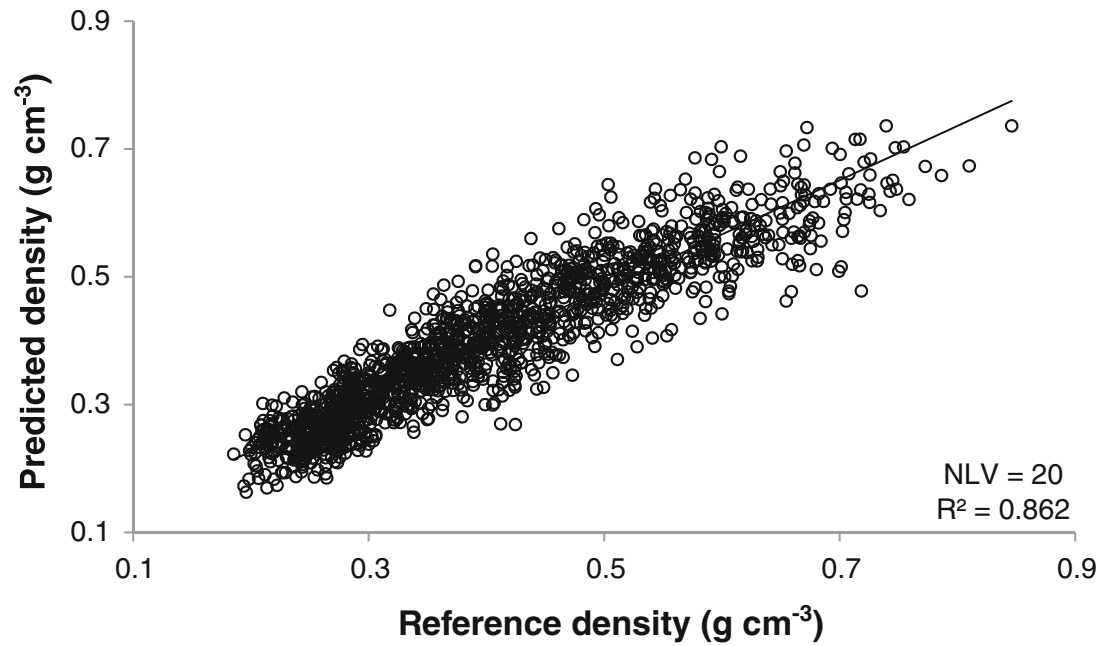


Fig. 6 RMSEP\% as a function of the reference density for a typical run (20 latent variables included)
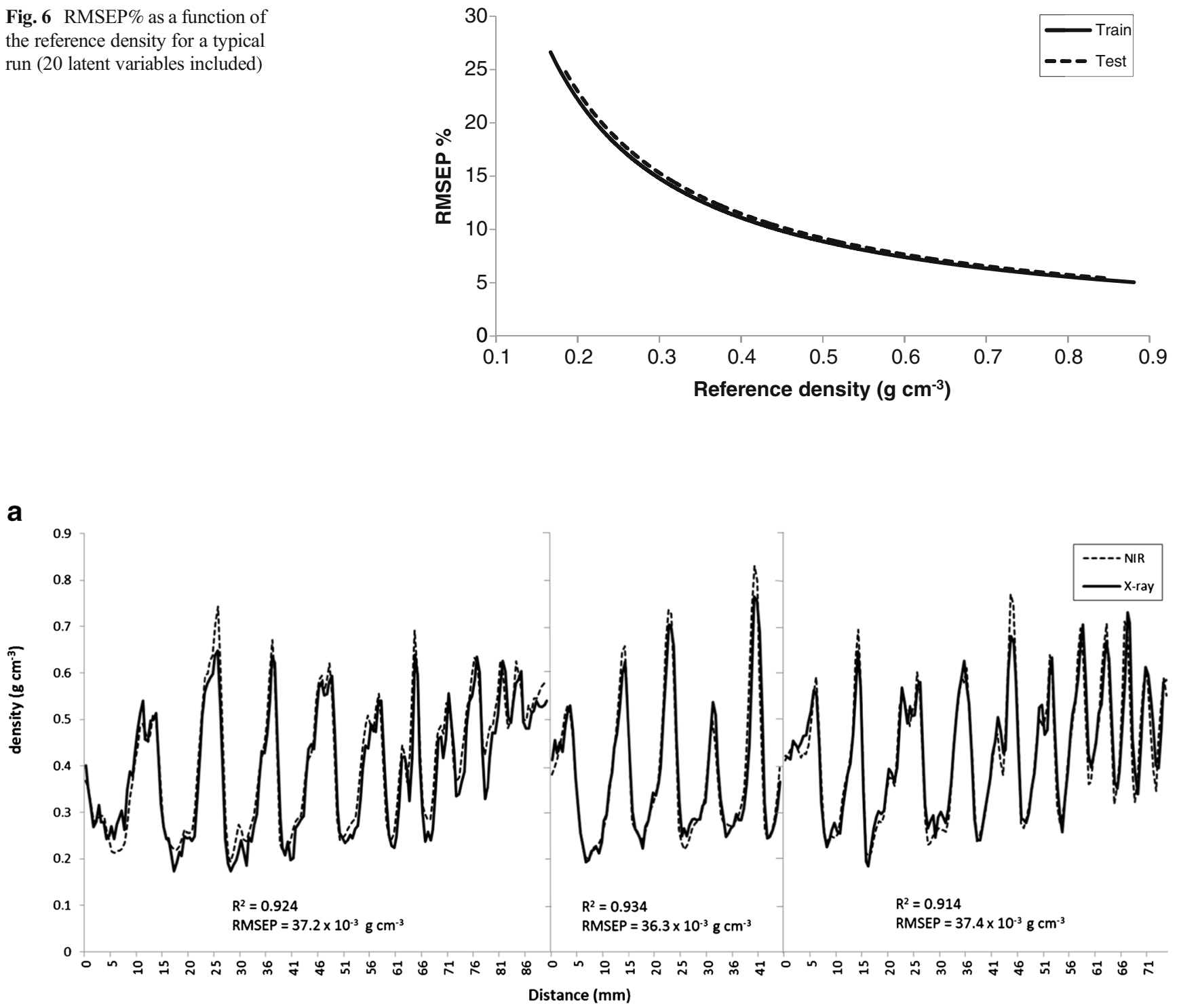

b

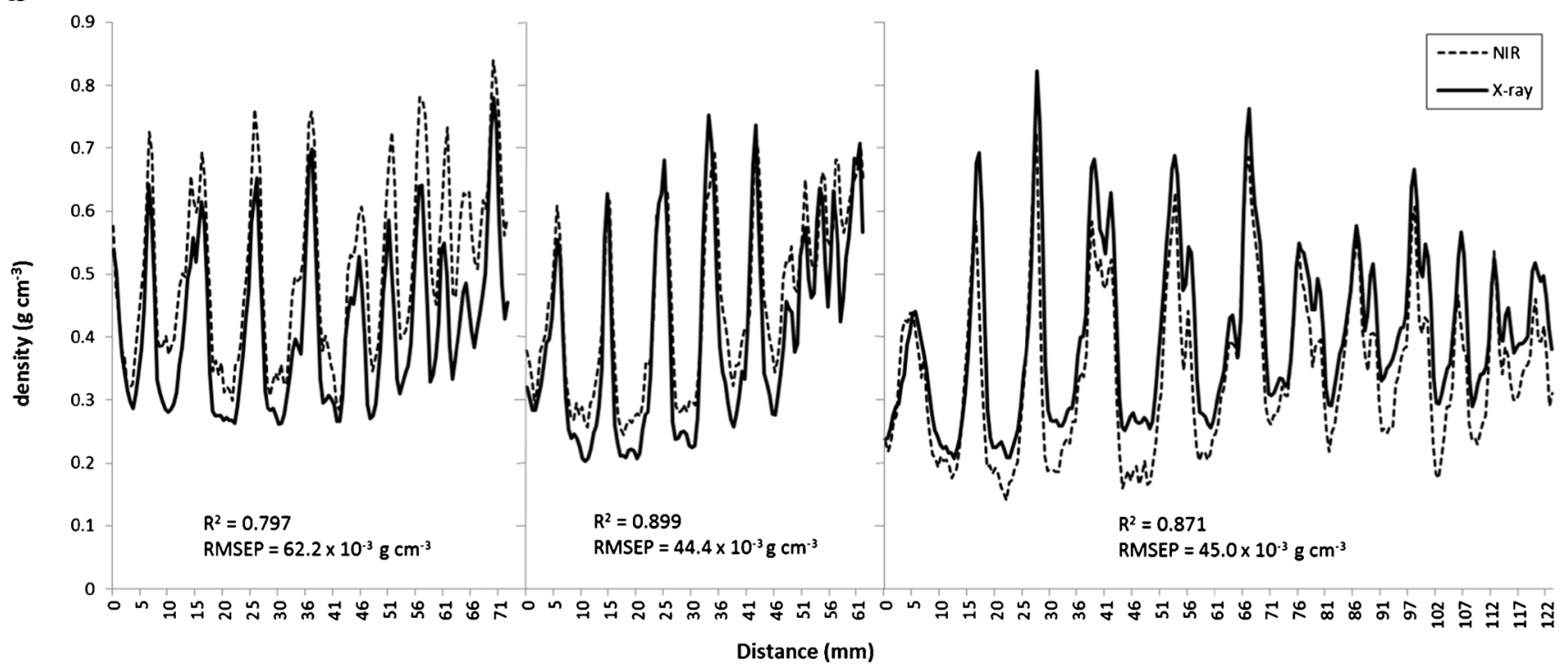

Fig. 7 Good (a) and poor (b) comparisons between X-ray and NIR-predicted microdensity profiles for six different pith-to-bark strips 

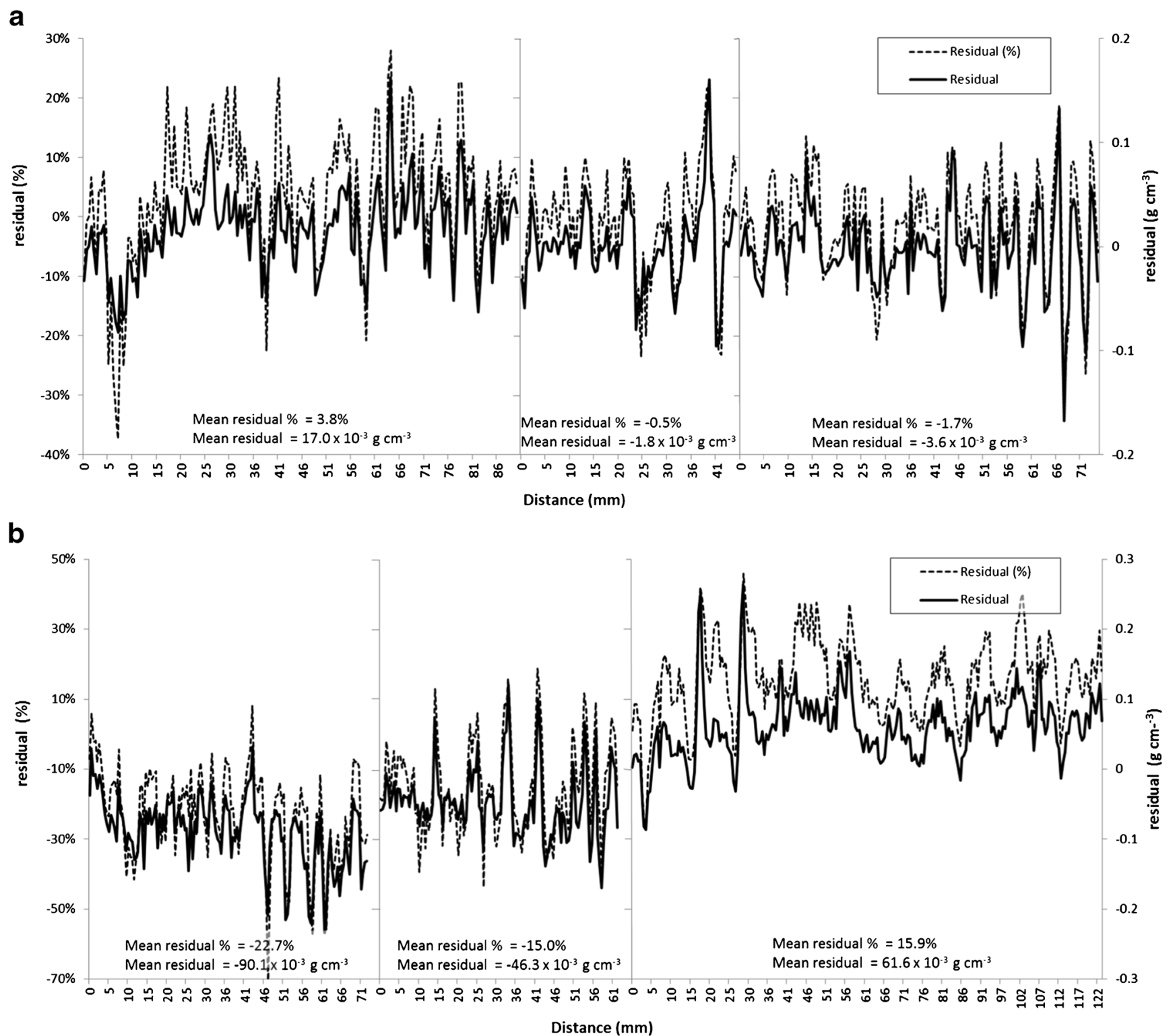

Fig. 8 Residual and residual\% for the same six pith-to-bark strips from previous figure. Good (a) and poor (b) comparisons

$43.1 \times 10^{-3} \mathrm{~g} \mathrm{~cm}^{-3}$ for the training group. For the validation group, the values are 0.895 and $47.1 \times 10^{-3} \mathrm{~g} \mathrm{~cm}^{-3}$, respectively. The RMSEP obtained are better than those found in studies using hyperspectral imaging (Fernandes et al. 2013a; Fernandes et al. 2013b).

According to Alves et al. (2012) the RER should be $\geq 4$ for screening calibration, $\geq 10$ to be acceptable for calibration for quality control, and $\geq 15$ for calibration for quantification. The curve here shows that four or more latent variables generate an RER value greater than 10 , which is acceptable for calibration for quality control. This means that the RER values obtained using more of 14 latent variables are closer to the frontier between calibration used for quality control and calibration used for quantification. These results are superior to those found in the literature summarized by Alves et al. (2012) for different wood density studies, with a range from 4.1 to 13.7. The ratio between the RMSEP values obtained from the validation and training groups ranges from 1.03 with 5 latent variables to 1.09 with 20 latent variables (calculated from Fig. 1). These results are also better than those presented by Alves et al. (2012).

Analysis of the residuals showed that a minimal displacement error between X-ray and NIRS measures can change considerably the density values obtained. The method robustness should be assessed considering the objective of the densitometry analysis. Future studies may address robustness analysis at ring level considering variables such as widths, mean densities, and earlywood/latewood proportions. 


\section{Conclusion}

We demonstrate that a fiber optic NIR spectrometer with a high-precision displacement system is capable of producing accurate measurements of intra-ring $P$. radiata density values with a spatial resolution of $0.5 \mathrm{~mm}$ approximately. Typical intra-ring density profiles for $P$. radiata growing in Chile show alterations in the profile shape such as false tree rings. Nevertheless, the NIR/PLSR method implemented addresses these anomalies in predicting tree ring profiles. It might be possible to apply this methodology successfully in other softwoods and hardwoods species.

The mean $R^{2}$ and RMSEP values for NIR/PLSR models relative to $\mathrm{X}$-ray densitometry values are 0.873 and $43.1 \times 10^{-3} \mathrm{~g} \mathrm{~cm}^{-3}$ for the training group. For the validation group, the values are 0.895 and $47.1 \times 10^{-3} \mathrm{~g} \mathrm{~cm}^{-3}$, respectively. The RMSEP obtained are better than those found in studies using hyperspectral imaging.

The ratio between the RMSEP values obtained from the validation and training groups was 1.09 , which is better than that reported in the literature. The ratio of the range (RER) value of 13.7 in this study is closer to the frontier between calibration used for quality control and calibration used for quantification. These results are even higher than some studies of wood density that do not employ spatial resolution.

Acknowledgements The principal author gratefully acknowledges plateau technique GENOBOIS and UR 0588 AGPF of INRA Val de Loire, France, for radiography.

\section{Compliance with ethical standards}

Funding This study was supported by FONDECYT Chile (Project No. 1150815) and DI-Universidad de Talca.

\section{References}

Acuna MA, Murphy GE (2007) Uso de espectroscopia infrarroja y análisis multivariado para predecir la densidad de la madera de pino oregón. Bosque 28(3):187-197. doi:10.4067/S071792002007000300002

Alves A, Santos A, Rozenberg P, Pâques L, Charpentier JP, Schwanninger M, Rodrigues J (2012) A common near infraredbased partial least squares regression model for the prediction of wood density of Pinus pinaster and Larix $\times$ eurolepis. Wood Sci Technol 46:157-175. doi:10.1007/s00226-010-0383-x

Downes G, Meder R, Bond H, Ebdon N, Hicks C, Harwood C (2011) Measurement of cellulose content, Kraft pulp yield and basic density in eucalypt woodmeal using multisite and multispecies near infrared spectroscopic calibrations. South For 73(3-4):181-186. doi: $10.2989 / 20702620.2011 .639489$

Downes G, Harwood C, Washusen R, Ebdon N, Evans R, White D, Dumbrell I (2014) Wood properties of Eucalyptus globulus at three sites in Western Australia: effects of fertiliser and plantation stocking. Aust Forestry 77(3-4):179-188. doi:10.1080/00049158.2014.970742
Fernandes A, Lousada J, Morais J, Xavier J, Pereira J, Melo-Pinto P (2013a) Measurement of intra-ring wood density by means of imaging VIS/NIR spectroscopy (hyperspectral imaging). Holzforschung 67:59-65. doi:10.1515/hf-2011-0258

Fernandes A, Lousada J, Morais J, Xavier J, Pereira J, Melo-Pinto P (2013b) Comparison between neural networks and partial least squares for intra-growth ring wood density measurement with hyperspectral imaging. Comput Electron Agric 94:71-81. doi:10.1016/j.compag.2013.03.010

Haddadi A, Leblon B, Burger J, Pirouz Z, Groves K, Nader J (2015) Using near-infrared hyperspectral images on subalpine fir board. Part 2: density and basic specific gravity estimation. Wood Mater Sci Eng 10(1):41-56. doi:10.1080/17480272.2015.1011231

Jones PD, Schimleck LR, So CL, Clark A, Daniels RF (2007) High resolution scanning of radial strips cut from increment cores by near infrared spectroscopy. IAWA J 28(4):473-484. doi:10.1163 /22941932-90001657

Li Y, Li P, Jiang L (2012) Prediction of larch wood density by nearinfrared spectroscopy and an optimal BP neural network using coupled GA and RSM. J Inf Comput Sci 13:3783-3794

Mevik BH, Werens R (2007) The pls package: principal component and partial least squares regression in R. J Stat Softw 18(2):1-24. doi:10.18637/jss.v018.i02

Mora CR, Schimleck LR, Isik F (2008) Near infrared calibration models for the estimation of wood density in Pinus taeda using repeated sample measurements. J Near Infrared Spectrosc 16(6):517-528. doi:10.1255/jnirs. 816

Kitamura R, Tsuchikawa S (2015) Construction of a novel densitometer that utilizes a near-infrared laser system with Douglas fir (Pseudotsuga menziesii). Wood Mater Sci Eng 10(1):69-74. doi:10.1080/17480272.2014.968873

Rodrigues JC, Fujimoto T, Schwanninger M, Tsuchikawa S (2013) Prediction of wood density using near infrared-based partial least squares regression models calibrated with X-ray microdensity. NIR news 24(2):4-8. doi:10.1255/nirn.1352

Rosso S, Muniz GIBD, Matos JLMD, Haselein CR, Hein PRG, Lopes MDC (2013) Estimate of the density of Eucalyptus grandis W. Hill ex Maiden using near infrared spectroscopy. Cerne 19(4):647-652. doi:10.1590/S0104-77602013000400015

Schimleck LR, Michell AJ, Raymond CA, Muneri A (1999) Estimation of basic density of Eucalyptus globulus using near-infrared spectroscopy. Can J For Res 29(2):194-201. doi:10.1139/cjfr-29-2-194

Schimleck LR, Evans R, Ilic J (2001) Estimation of Eucalyptus delegatensis wood properties by near infrared spectroscopy. Can J For Res 31:1671-1675. doi:10.1139/x01-101

Schimleck LR, Evans R (2003) Estimation of air-dry density of increment cores by near infrared spectroscopy. Appita J 56(4):312-317 Issn: $1038-6807$

Tsuchikawa S (2007) A review of recent near infrared research for wood and paper. Appl Spectrosc Rev 42:43-71. doi:10.1080 /05704920601036707

Wentzel-Vietheer M, Washusen R, Downes G, Harwood C, Ebdon N, Ozarska B, Baker T (2013) Prediction of non-recoverable collapse in Eucalyptus globulus from near infrared scanning of radial wood samples. Eur J Wood Wood Prod 71(6):755-768. doi:10.1007 /s00107-013-0735

Zamudio F, Baettyg R, Guerra F, Vergara A, Rozenberg P (2002) Genetic trends in wood density and radial growth with cambial age in a radiata pine progeny test. Ann For Sci 59:541-549. doi:10.1051 /forest:2002039

Zamudio F, Rozenberg P, Baettig R, Vergara A, Yañez M, Gantz C (2005) Genetic variation of wood density components in a radiata pine progeny test located in the south of Chile. Ann For Sci 62:105114. doi:10.1051/forest:2005002 